\title{
Ethical publication of research on genetics and genomics of biological material: guidelines and recommendations
}

\author{
Maria Eugenia D'Amato ${ }^{\mathrm{a}, *}$, Martin Bodner ${ }^{\mathrm{b}}$, John M. Butler ${ }^{\mathrm{c}}$, Leonor Gusmão ${ }^{\mathrm{d}}$, Adrian Linacre ${ }^{\mathrm{e}}$, \\ Walther Parson ${ }^{b, f}$, Peter M. Schneider ${ }^{g}$, Peter Vallone ${ }^{c}$, Angel Carracedo ${ }^{\mathrm{h}}$ \\ ${ }^{a}$ Forensic DNA Laboratory, Department of Biotechnology, Faculty of Natural Sciences, University of the Western Cape, South Africa \\ ${ }^{\mathrm{b}}$ Institute of Legal Medicine, Medical University of Innsbruck, Innsbruck, Austria \\ ${ }^{\mathrm{c}}$ National Institute of Standards and Technology, Gaithersburg, MD, USA \\ ${ }^{\mathrm{d}}$ DNA Diagnostic Laboratory, State University of Rio de Janeiro, Brazil \\ ${ }^{\mathrm{e}}$ Flinders University, College of Science \& Engineering, Adelaide, Australia \\ ${ }^{\mathrm{f}}$ Forensic Science Program, The Pennsylvania State University, University Park, PA, USA \\ ${ }^{\mathrm{g}}$ Institute of Legal Medicine, University Clinic and Faculty of Medicine, University of Cologne, Cologne, Germany \\ ${ }^{\mathrm{h}}$ Institute of Forensic Sciences, Genomic Medicine Group-CIBERER, University of Santiago de Compostela, Spain
}

\section{A R T I C L E I N F O}

\section{Keywords:}

Research ethics

Genetics

Genomics

Forensics

\begin{abstract}
A B S T R A C T
Forensic Science International: Genetics and Forensic Science International: Reports communicate research on a variety of biological materials using genetics and genomic methods. Numerous guidelines have been produced to secure standardization and quality of results of scientific investigations. Yet, no specific guidelines have been produced for the ethical acquisition of such data. These guidelines summarize universally adopted principles for conducting ethical research on biological materials, and provide details of the general procedures for conducting ethical research on materials of human, animal, plant and environmental origin. Finally, the minimal ethics requirements for submission of research material are presented.
\end{abstract}

\section{Foreword}

These ethical guidelines are being jointly adopted by and therefore jointly published in Forensic Science International: Genetics and Forensic Science International: Reports.

With an increase of logistical complexity in the process of acquiring biological material, generating genetic and genomic information, sharing and distributing of results, and internationalization of research, the ethical check points and regulations of the above mentioned activities have also become more complex. These reach to the collection, transport, storage, data generation, data utilization, data sharing and extent of details revealed in publications, which are subject to national regulations and international legally binding agreements. These standards and principles are not always tightly abided to and more transparency in the adoption of these principles, such as access to consent forms and other ethics documentation, has been claimed [1].

The journals Forensic Science International: Genetics, Forensic Science International: Genetics Supplement Series and Forensic Science International: Reports are adopting the following principles as prerequisites for publication:
1. General ethics principles that are regulated by national boards and represent widely signed international agreements:

(i) The principles of state sovereignty rights of their biological, genetic and genomic resources within their boundaries, with the exception of biological material in areas beyond national jurisdictions [2], as explicit in Article 15.1 of the Convention of Biological Diversity (CBD) [3] "Recognizing the sovereign rights of States over their natural resources, the authority to determine access to genetic resources rests with the national governments and is subject to national legislation."

(ii) The principles of common heritage of humankind [4] applying to biological material located outside any national jurisdiction, e.g. high seas beyond 200 nautical miles from national coastlines, sea bed, Antarctica, atmosphere and space.

2. Universal declarations, instruments and principles that require implementations in state members:

(i) The World Medical Association Declaration of Helsinki biomedical research on human subjects (updated regularly) [5].

(ii) The Council for International Organizations of Medical Sciences guidelines for health-related research in human subjects [6].

\footnotetext{
* Corresponding author.

E-mail address: medamato@uwc.ac.za (M.E. D’Amato).
} 
(iii) The UNESCO principles on human rights and bioethics [7-9].

(iv) World Medical Association Declaration of Taipei on databases and biobanks [10].

3. Universal declarations and principles drafted by independent organizations that have been widely adopted by the scientific community:

(i) The Nuffield Council of Bioethics guide for research with animals [11].

An example of national implementation of ethics principles and guidelines is the U.S. Federal Policy for the Protection of Human Subjects ('Common Rule') [12,13].

This document further summarizes ethical guidelines and requirements for the publication of genetic and genomic data in Forensic Science International: Genetics, Forensic Science International: Genetics Supplement Series and Forensic Science International: Reports. These journals publish scientific research on a wide variety of DNA sources, ranging from those whose collection require direct contact with living sources of DNA (e.g. human biological material, wildlife, plants, microorganisms, environmental samples) to others, which do not (e.g. food, animal products, post-mortem and archaeological specimen, natural medicine products and other items of biological origin subjectable to authentication procedures).

Most often, the material under investigation (DNA sequence of whole genomes or partial genome fragments, RNA sequences, methylation, expression patterns and byproducts of gene expression) is subjected to different ethics and research regulations according to the category of living source. Therefore, we organized this guideline with instructions for ethical research on humans, wildlife and environment, and organic products susceptible to authentication.

Manuscripts submitted to these journals will be referred to peer reviewers, only if demonstrating, that they comply with the adopted criteria as well as the journal policies on this matter. Together with the manuscript, the following supporting documentation is requested:

(i) ethical approval in the country of collection by the appropriate local ethical committee or institutional review board,

(ii) ethical approval in the country of experimental work according to local legislation; if material collection and experimentation are conducted in different countries, both (i) and (ii) are required,

(iii) template of consent forms in case of human material as approved by the relevant ethical committee, ${ }^{1}$

(iv) approved export/ import permits as applies.

These supporting documents will be requested prior to submission for peer evaluation. All above (except the provision of the consent forms template) are also valid for other than human sources of biological material.

In addition to the specific requirements listed in the recommendations, authors must declare in the submitted manuscripts that these guidelines have been strictly followed.

The adopted criteria, guidelines and recommendations for the different sources of genetic material are developed below.

\section{Human biological material}

We understand human biological material (HBM) encompasses all biological material of human origin, including organs, tissues, bodily fluids, teeth, hair and nails, DNA, RNA and metabolites, obtained for research purposes by direct donation from an individual. We extend the concept of individual HBM to "interactive community of human cells and microbial cells" [14] for the consensual nature of the access to our

\footnotetext{
${ }^{1}$ Note that only a blank copy of the template is required. Written consent forms must be retained by the authors.
}

microbiomes and pathogens.

For the publication of all material of human origin, the manuscripts must indicate:

(i) the ethics committee or regulatory board that approved the research methods and the development of the study. In case of country/ies of collection being different from the country of analysis, ethical approval from all involved parties is necessary.

(ii) a statement that the approved procedures and protocols were followed, and

(iii) a statement that all participants signed the approved consent form indicating fully informed consent.

A comprehensive list of national regulatory boards worldwide has been compiled by the US Department of Health (https:// bioethicsresearchreview.tghn.org/international-compilation-humanresearch-standards/), and also for regulations in Sub Saharan Africa [15]. Additional information can be found at the Health Research Web site (https://healthresearchweb.org/), the Training and Resources in Research Ethics Evaluation consortium (TRREE) (https://elearning. trree.org/) site, and the McGill University database of international, national and regional laws and regulations for research in human population genetics (www.popgen.info).

Personal data of all participating individuals must be protected from any form of sharing or public release. We recommend that (in addition to any specific local or institutional requirements) the informed consent document contains clauses about the aims and scope of the study, the risks and benefits of participating, disclosure of the fate and utilization of the individual's donated biological material, including the possibility of it being shared with national and international collaborators, and to make appropriate provision for withdrawal from the study, in compliance with the UNESCO declaration of human genome and human rights [7].

Secondary use of biological material is understood as the utilization of biological samples for other purposes than the primary goal for which the study was approved. Unless the ethics approval and informed consent made provision for the extended use of samples, the study will not be accepted for publication. Participation of illiterate people in the form of video recorded verbal consent and utilization of samples that have not originated from free will participation (e.g. prisoners of wars, detainees by law enforcement agencies, adults with no mental capacity to provide consent, embryos) will not be accepted unless covered by national legislation, which must be indicated along with the corresponding permit. Participation of minors, as defined by the respective country of origin's legislation, will require approval by their legal guardian(s).

\subsection{Special case: population genetic/ genomic data}

The nature of the forensic population genetic research implies acquiring information about the genetic identity of participants. The public release of genetic and genomic information must be in concordance with the general ethic principles adopted by the journals, and the consent forms signed by the voluntary donors. This type of work may involve minorities, indigenous peoples and vulnerable population groups. Often these peoples come from different cultural background than those of researchers. All communities should be approached with sensitivity, respecting their culture, traditions, and religious beliefs [16]. Liaison through their representatives and dialogue before collection of samples and after obtaining results are encouraged. As previously stated "research should refrain from taking either active or passive advantage of loopholes and weaknesses in the governance systems of another country in order to perform research that would be legally or ethically unacceptable in their own country [17]." Conflict between minorities and researchers were experienced by the San [18], and inappropriate use of samples of Chinese minorities [19], Native 
Americans [20], and other loose ethical practices in the African continent have been reported [21]. Active participation of indigenous peoples in drafting guidelines [22-24] and guidelines to empower native communities are a growing trend [24-26].

It is imperative to consider that a collection of individual results have impact not only on the individual participants but also on the community the individual belongs to [16]. Local cultural knowledge and understanding is essential in the process of liaison with communities. Small communities, indigenous peoples and minorities may favor the concept of collective consent [18], and even differences between developing countries and industrialized societies exist in the type of adopted consents [27]. The involvement of local researchers becomes essential when these studies are conducted by multinational teams, for local researchers have better knowledge of the studied populations and communities. Documentation from all ethics review boards (from countries subjected to sampling to countries conducting the experimental work) will be requested as prerequisite for evaluation of the manuscripts.

In addition, human movements, migrations and displacements may determine temporal fluctuations or directional changes in populations composition, e.g. immigration into metropolitan areas, mass migrations away from conflict areas, etc. For this reason, the authors must indicate the date of collection.

\subsection{Special cases: biobanks and commercial sources}

National regulations regarding research on biobanked material are limited and some countries do not have a policy on the topic $[14,28,29]$ with various access policies [30]. Moreover, guidance is not always clearly defined and leeway for unsound ethical practices seems plausible [31]. The journals adopt the criteria of compliance with the access and regulations of the accessed databank and the ethical research permits issued in the country of research. Authors must provide supporting documentation.

\subsection{Special case: human remains}

Explicit regulations regarding access to biological material from deceased humans are even scarcer than the above. Research on postmortem cases can require consent from next-of-kin under some regulations [32]. Access to human remains by exhumation or excavations may be regulated by different boards, professional and governmental organizations, e.g., archaeological approval or law enforcement regulations to access mass graves with professional forensic anthropology teams. Supporting documentation will be requested.

\section{Animal and plant biological material}

Manuscripts based on animal and plant living organisms must provide a statement indicating the ethics regulatory board that approved the methods of the study, the reference number or code of the approval, and provide details of the protocols and procedures applied in the study abiding to national legislation. International research involving activities in different countries will require multiple ethics approvals.

We strongly suggest compliance with international agreements and regulations, e.g. the Convention on Biological Diversity (CBD) [3], and the Convention on International Trade in Endangered Species of Wild Fauna and Flora (CITES) [33]. As indicated above, we abide to the principles of the CBD Article 15.1. Not being compliant with this principle will result in rejection of the submitted manuscripts.

If species under study fall within the CITES guidelines, we request authors to comply with the CITES trade requirements in international research, e.g. [34]. In addition, if species of interest fall under the CITES [35] or the International Union for Conservation of Nature (IUCN) [36] conservation categories, their conservation status must be indicated, along with a statement that all work had the required approval. We also suggest following the ARRIVE guidelines for reporting results, which have been compiled by scientists, journal editors, statisticians, and funders and were widely adopted by the scientific community [37].

\subsection{Animals in genetics and genomics research ${ }^{2}$}

The utilization of animals in scientific experimentation is regulated by institutional, national and transnational guidelines. Authors must provide a statement indicating that ethical procedures were followed, and which board approved the experimental approaches in compliance with the appropriate guidelines. Guidelines for the US [38,39], UK [40] and Europe [41] are of public knowledge, in addition to the widely adopted Nuffield Council on Bioethics guidelines [11].

\subsection{Wildlife}

The methodology for accessing and sampling wild plants and animals that are living organisms must be approved by a specialized ethics regulatory board.

The manuscripts should disclose the committee or board that granted ethical approval and indicate that the study abided to local policies and regulations. Recommendations for ethical fieldwork have been reviewed and adopted for publication by specialized journals [42]. We recommend that these principles of non-disturbance of subjects and environment are applied. Modes of accessing biological material fall in different categories: lethal, invasive and non-invasive DNA sampling techniques [43]. Improvements in DNA extraction techniques and genotyping methods with non-invasive techniques [44] can assist in the humane treatment of animals and minimize all possible stress and pain. The protocol/s followed for accessing the biological material should be disclosed and mention whether a trained professional conducted the manipulation of animals in the case of adoption of non-lethal invasive techniques (e.g. sedation and blood extractions by veterinarians). Animal microbiomes are considered in this category. The application of lethal techniques will not be accepted.

Further, the conservation status of species under study, as determined by international organizations, e.g. the International Union for Conservation of Nature and Natural Resources (IUCN), must be indicated.

\subsection{Special cases: biobanks}

Wildlife and plant biobanks that support access for research activities have policies in place that are often regulated as material transfer agreements or research agreements, e.g. [45]. Domesticated animals and plants are also subjected to biobanking which are hosted by a large variety of institutions [46]. Research based on material accessed in biobanks must state the compliance with their regulations about terms of access, aim of research and publication of results.

\section{Environmental DNA}

Metagenomics and metabarcoding environmental methods must have been approved by a relevant committee regulating or overseeing research in this field. We adopt the same principles of natural resources sovereignty indicated above (CBD Article 15.1) as well as the principles of minimal disturbance to the environment, and humane treatment of animals. The ethics research approval by a local administration or regulatory board must be disclosed. The manuscript must include a statement indicating compliance to local policies.

\footnotetext{
${ }^{2}$ Complete guidelines for experimentation with animals in non-genetics or genomics research will be published soon in Forensic Science International.
} 


\section{Animal and plants products}

This category involves research on byproducts of animal and plant origin, such as food, medicines, and other valuable material subjected to illegal trafficking, e.g., tusks. To the best of our knowledge, the access to market products for research purposes are not subjected to ethics regulations, but the research projects might need to be registered at local institutions. Supporting documentation, if it applies, will be requested.

\section{Beyond research ethics approval: post publication policies and conscientious objection}

Documentation supporting compliance with the publication guidelines must be provided with submitted manuscripts. Contravention of national legislation, international agreements, or breach of ethical principles in any form, will determine rejection of original submissions. If, after investigation and following due process, contraventions are proved after publication, manuscript may be retracted or otherwise corrected in accordance with the journal's ethics guidelines.

The WHO guidelines [16] states "While informed consent to research is important, the fact that a participant or surrogate may be willing to consent to research does not, in itself, mean that the research is ethically acceptable." For example, recent scientific work on wildlife with appropriate ethics research permits was not granted publication as the work was determined to be unethical by the journal editorial board [42].

The editorial board is solely and independently responsible for deciding which of the articles submitted to the journals should be published, (https://www.elsevier.com/about/company-information/ policies/editorial-independence). The validation of the work in question and its importance to researchers and readers must always underwrite such decisions. They may confer with other editors or reviewers (or society officers) in making these decisions.

\section{Resolution of conflicts}

If for any exceptional reason (i.e. local legislation) any of the requirements cannot be completely fulfilled, the authors should explain in the letter of submission the motivation. The editors will establish, along with the publisher, a transparent and independent mechanism for appeal against editorial decisions.

\section{Declaration of Competing Interest}

The authors have no competing interests to declare.

\section{Acknowledgements}

The authors are grateful to the anonymous colleagues who provided critical feedback on this paper.

\section{References}

[1] G.E. Wright, A.A. Adeyemo, N. Tiffin, Informed consent and ethical re-use of African genomic data, Hum. Genomics 8 (2014) 18, https://doi.org/10.1186/ s40246-014-0018-7.

[2] United Nations General Assembly, Resolution 3016(XXVII) Permanent Sovereignty over Natural Resources of Developing Countries, (1972) https://digitallibrary.un. org/record/748907? ln = en.

[3] CBD Secretariat, Convention on Biological Diversity, (1992) https://www.cbd.int/ doc/legal/cbd-en.pdf.

[4] C. Rhodes, Potential international approaches to ownership/control of human genetic resources, Health Care Anal. 24 (2016) 260-277, https://doi.org/10.1007/ s10728-015-0300-4.

[5] World Medical Association declaration of Helsinki: ethical principles for medical research involving human subjects, JAMA - J. Am. Med. Assoc. 310 (2013) 2191-2194, https://doi.org/10.1001/jama.2013.281053.

[6] CIOMS, Council for International Organizations of Medical Sciences, World Health
Organization. International Ethical Guidelines for Biomedical Research Involving Human Subjects, World Health Organization, Geneva, Switzerland, 2002 https:// cioms.ch/publications/product/international-ethical-guidelines-for-biomedicalresearch-involving-human-subjects- 2 .

[7] UNESCO, Universal Declaration on the Human Genome and Human Rights, (1997) https://unesdoc.unesco.org/ark:/48223/pf0000110220.

[8] UNESCO, International Declaration on Human Genetic Data, (2003) https:// unesdoc.unesco.org/ark:/48223/pf0000133171.

[9] UNESCO, Universal Declaration on Bioethics and Human Rights, (2005) https:// unesdoc.unesco.org/ark:/48223/pf0000142825.

[10] WMA, WMA Declaration of Taipei on Ethical Considerations Regarding Health Databases and Biobanks, WMA - The World Medical Association, Taipei, 2002 https://www.wma.net/policies-post/wma-declaration-of-taipei-on-ethicalconsiderations-regarding-health-databases-and-biobanks/.

[11] Nuffield Council on Bioethics, The Ethics of Research Involving Animals, London, (2005) 1904384102

[12] J. Menikoff, J. Kaneshiro, I. Pritchard, The common rule, updated, N. Engl. J. Med. 376 (2017) 613-615, https://doi.org/10.1056/NEJMp1700736.

[13] US Department of Health and Human Services, Federal Policy for the Protection of Human Subjects, (2017) https://www.hhs.gov/ohrp/regulations-and-policy/ regulations/common-rule/index.html.

[14] T. Rees, T. Bosch, A.E. Douglas, How the microbiome challenges our concept of self, PLoS Biol. 16 (2018) e2005358, https://doi.org/10.1371/journal pbio.2005358.

[15] F. Barchi, M. Little, National ethics guidance in Sub-Saharan Africa on the collection and use of human biological specimens: a systematic review, BMC Med. Ethics 17 (2016) 64, https://doi.org/10.1186/s12910-016-0146-9.

[16] Standards and Operational Guidance for Ethics Review of Health-Related Research with Human Participants, World Health Organization, 2011 (Accessed 18 December 2019), http://www.ncbi.nlm.nih.gov/pubmed/26269877.

[17] D. Schroeder, J. Cook, F. Hirsch, S. Fenet, V. Muthuswamy, Introduction, in: D. Schroeder, J. Cook, F. Hirsch, S. Fenet, V. Muthuswamy (Eds.), Ethics Dumping: Case Studies from North-South Research Collaborations, Springer International Publishing, Cham, 2018, https://doi.org/10.1007/978-3-319-64731-9.

[18] R. Chennells, A. Steenkamp, International genomics research involving the San people, in: D. Schroeder, J. Cook, F. Hirsch, S. Fenet, V. Muthuswamy (Eds.), Ethics Dumping: Case Studies from North-South Research Collaborations, Springer International Publishing, 2018, pp. 15-22, https://doi.org/10.1007/978-3-31964731-9_3.

[19] Y. Zhao, W. Zhang, An International collaborative genetic research project conducted in China, in: D. Schroeder, J. Cook, F. Hirsch, S. Fenet, V. Muthuswamy (Eds.), Ethics Dumping: Case Studies from North-South Research Collaborations, Springer International Publishing, 2018, pp. 71-80, https://doi.org/10.1007/9783-319-64731-9_9.

[20] N.A. Garrison, Genomic justice for Native Americans: impact of the Havasupai case on genetic research, Sci. Technol. Hum. Values. 38 (2013) 201-223, https://doi. org/10.1177/0162243912470009.

[21] L. Nordling, African scientists call for more control of their continent's genomic data, Nature News 14 (7) (2018), https://doi.org/10.1038/d41586-018-04685-1.

[22] M. Hudson, A. Beaton, M. Milne, W. Port, K. Russell, B. Smith, V. Toki, L. Uerata, P. Wlicox, Te Mata Ira, Guidelines for Genomic Research with Māori, (2016) (Accessed 19 January 2020), https://www.waikato.ac.nz/_data/assets/pdf_file/ 0018/321534/Te-Mata-Ira-Genome-Research-Guidelines.pdf.

[23] S.A.S. Institute, San Code of Research Ethics, (2017) http://trust-project.eu/wpcontent/uploads/2017/03/San-Code-of-RESEARCH-Ethics-Booklet-final.pdf.

[24] S. Reardon, Navajo nation reconsiders ban on genetic research, Nature 550 (2017) 165-166, https://doi.org/10.1038/nature.2017.22780.

[25] K.G. Claw, M.Z. Anderson, R.L. Begay, K.S. Tsosie, K. Fox, N.A. Garrison, A.C.C. Bader, J. Bardill, D.A.A. Bolnick, J. Brooks, A. Cordova, R.S. Malhi, N. Nakatsuka, A. Neller, J.A.A. Raff, J. Singson, K. TallBear, T. Vargas, J.M. Yracheta, A framework for enhancing ethical genomic research with Indigenous communities, Nat. Commun. 9 (2018) 2957, https://doi.org/10.1038/ s41467-018-05188-3.

[26] H3Africa Community Engagement Working Group, H3Africa Guidelines for Community Engagement (version two), (2017) https://h3africa.org/wp-content/ uploads/2018/05/CE\%20Revised\%20Guidelines_Final_September\%202017\%20\% 281\%29.pdf.

[27] M. Sather, A. Dhai, Laws, regulations and guidelines of developed countries, developing countries in Africa, and BRICS regions pertaining to the use of human biological material (HBM) in research, South Afr. J. Bioeth. Law. 5 (2012) 51-54.

[28] J. de Vries, S.N. Munung, A. Matimba, S. McCurdy, O. Ouwe Missi Oukem-Boyer, C. Staunton, A. Yakubu, P. Tindana, Regulation of genomic and biobanking research in Africa: a content analysis of ethics guidelines, policies and procedures from 22 African countries, BMC Med, Ethics 18 (2017) 8, https://doi.org/10.1186/ s12910-016-0165-6.

[29] K. Beier, S. Schnorrer, N. Hoppe, C. Lenk, The ethical and legal regulation of human tissue and biobank research in Europe, Proceedings of the Tiss. EU Project, Universitätsverlag Göttingen, 2011.

[30] H. Langhof, H. Kahrass, S. Sievers, D. Strech, Access policies in biobank research: what criteria do they include and how publicly available are they? A cross-sectional study, Eur. J. Hum. Genet. 25 (2017) 293-300, https://doi.org/10.1038/ejhg.2016. 172.

[31] J.W. Ashcroft, C.C. Macpherson, The complex ethical landscape of biobanking, Lancet. Public Heal. 4 (2019) e274-e275, https://doi.org/10.1016/S2468 2667(19)30081-7.

[32] L.J. Heathfield, S. Maistry, L.J. Martin, R. Ramesar, J. de Vries, Ethical considerations in forensic genetics research on tissue samples collected post-mortem in Cape 
Town, South Africa, BMC Med, Ethics 18 (2017) 66, https://doi.org/10.1186/ s12910-017-0225-6.

[33] CITES, Convention on International Trade in Endangered Species. 27 UST 1087; TIAS 8249; 993 UNTS 243, (1992) https://www.cites.org/eng/disc/text.php.

[34] L. Official Journal of the European Union, COMMISSION REGULATION (EC) No 865/2006. Laying Down Detailed Rules Concerning the Implementation of Council Regulation (EC) No 338/97 on the Protection of Species of Wild Fauna and Flora by Regulating Trade Therein, (2006) https://eur-lex.europa.eu/legal-content/EN/ $\mathrm{TXT} / \mathrm{PDF} /$ ?uri $=$ CELEX:32006R0865\&from $=\mathrm{EN}$.

[35] CITES, Appendices, CITES, 2019 https://www.cites.org/eng/app/appendices.php (Accessed 19 January 2020).

[36] IUCN, The IUCN Red List of Threatened Species. Version 2019-3, (2019) www. iucnredlist.org.

[37] C. Kilkenny, W.J. Browne, I.C. Cuthill, M. Emerson, D.G. Altman, Improving bioscience research reporting: the ARRIVE guidelines for reporting animal research, PLoS Biol. 8 (2010) e1000412, https://doi.org/10.1371/journal.pbio.1000412.

[38] Guide for the Care and Use of Laboratory Animals, National Research Council, Washington DC, 1996, https://doi.org/10.17226/5140.

[39] National Research Council (US) Committee for the Update of the Guide for the Care and Use of Animals, 8th edition, Guide for the Care and Use of Laboratory Animals, Washington DC, 2011.

[40] The Animals (Scientific Procedures) Act 1986 Amendment Regulations, United Kingdom, (2012) https://assets.publishing.service.gov.uk/government/uploads/
system/uploads/attachment_data/file/265691/Animals_Scientific_Procedures_ Act_1986.pdf.

[41] Directive 2010/63/EU of the European Parliament and of the Council of 22 September 2010 on the Protection of Animals Used for Scientific Purposes, Off. J. Eur. Union, 2010 276/3. https://eur-lex.europa.eu/legal-content/EN/TXT/PDF/? uri $=$ CELEX:32010L0063\&from $=$ EN.

[42] M.J. Costello, K.H. Beard, R.T. Corlett, G.S. Cumming, V. Devictor, R. Loyola, B. Maas, A.J. Miller-Rushing, R. Pakeman, R.B. Primack, Field work ethics in biological research, Biol. Conserv. 203 (2016) 268-271, https://doi.org/10.1016/j. biocon.2016.10.008.

[43] M.A. Zemanova, Poor implementation of non-invasive sampling in wildlife genetics studies, Rethink. Ecol. 4 (2019) 119-132, https://doi.org/10.3897/ rethinkingecology.4.32751.

[44] A. Beja-Pereira, R. Oliveira, P.C. Alves, M.K. Schwartz, G. Luikart, Advancing ecological understandings through technological transformations in noninvasive genetics, Mol. Ecol. Resour. 9 (2009) 1279-1301, https://doi.org/10.1111/j.17550998.2009.02699.x.

[45] P. Bartels, A. Kotze, Wildlife biomaterial banking in Africa for now and the future, J. Environ. Monit. 8 (2006) 779, https://doi.org/10.1039/b602809h.

[46] L.F. Groeneveld, S. Gregusson, B. Guldbrandtsen, S.J. Hiemstra, K. Hveem, J. Kantanen, H. Lohi, L. Stroemstedt, P. Berg, Domesticated animal biobanking: land of opportunity, PLoS Biol. 14 (2016) e1002523, https://doi.org/10.1371/journal. pbio.1002523. 